\title{
Temporal variables and trial discreteness in lever-press avoidance'
}

\author{
MICHAEL COLE ${ }^{2}$ AND EDMUNd FANTINO
}

YALE UNIVERSITY

Discrete trials were introduced into discriminated leverpress avoidance learning in rats by employing a retractable lever. The effects of CS-UCS and inter-trial (ITI) intervals were investigated using both retractable and non-retractable levers. The retractable lever groups outperformed the nonretractable lever groups by a highly significant margin early in training but this difference disappeared within 150 trials. Similarly, ITI and CS-UCS intervals affected performance only in the first 100 trials.

In a recent experiment (Fantino, Sharp, \& Cole, 1966) it was shown that removing the rat from the experimental chamber between trials significantly facilitated leverpress avoidance. The Fantino et al procedure produced levels of avoidance responding on a par with comparable shuttlebox results (Low \& Low, 1962). It was demonstrated that the door-drop CS which is usually a part of the discrete trial procedure was one critical variable. However, it was not clear whether a second critical factor in this experiment was the fact that the animal was removed from the generally aversive environment, or whether the use of discrete trials, per se, could account for the enhanced performance.

The present experiment was designed to evaluate the effect of discrete trials without removing $S$ from the experimental chamber. Discreteness was produced by the simple expedient of removing the lever after each response. In addition to comparing the performance of groups trained using a retractable lever with a group trained under normal lever-press conditions, we sought to evaluate the effects of two additional factors, CS-UCS interval and ITI, when discrete trials are produced by the retractable lever.

\section{Method}

The Ss were 108 male albino rats (Sprague-Dawley strain, obtained from Holtzman Company) which were 90-110 days old upon arriving at the laboratory.

The experimental chamber was 11 in. $x 7$ in. $x 13$ in. box. A retractable lever (Lehigh Valley Electronics) protruded from one wall. It had a grid floor through which a $1 \mathrm{ma}$ shock could be administered. The lever was automatically retracted when $\mathrm{S}$ responded and automatically re-inserted into the box after onset of the $\mathrm{CS}$. The box was enclosed inside a regrigerator shell to mask extraneous stimuli. The refrigerator also housed the shock scrambler (Lehigh Valley Model No. 131155) and a 6-w bulb.

At the start of the first experimental session the rat was placed inside the chamber. After a minute of adaptation time the light and the shock scrambler were turned on. This light-noise complex served as the CS.
If, after 3 sec., $\mathrm{S}$ did not press the lever, shock was applied through the grid floor. The Ss were shaped to escape the shock by pressing the lever.During shaping, the ITI was $7 \mathrm{sec}$. and the CS-UCS interval was $3 \mathrm{sec}$. After an average of 10 shaping trials all the Ss readily escaped the shock. The first experimental session then began. Nine groups, each containing nine Ss, were run with the retractable-lever; after depressing the lever to avoid or escape shock, the lever was automatically retracted. The lever was re-introduced at the same time as CS onset. For these Ss then, the emergence of the lever may be considered as part of the CS. These nine groups were run in a 3 by 3 factorial design in which ITI and CS-UCS interval were varied. The three ITIs were 15 sec., 30 sec., and 60 sec. The three CS-UCS intervals were 3 sec., 5 sec., and $10 \mathrm{sec}$. In addition, three groups containing nine Ss each, were run with a non-retractable lever. These Ss were all run with an ITI of $15 \mathrm{sec}$. The three non-retractable lever groups differed with respect to the CS-UCS interval. The three intervals used were $3 \mathrm{sec} ., 5 \mathrm{sec} .$, and $10 \mathrm{sec}$.

All Ss were run for three daily sessions of 50 trials each. Shaping occurred only on day 1 . On the third day all Ss were run with a CS-UCS interval of 5 sec. to control for the differential opportunity to avoid afforded Ss with differing CS-UCS intervals (Bitterman, 1965).

\section{Results}

The square root of the number of avoidance responses for each block of 10 trials is the basic datum computed

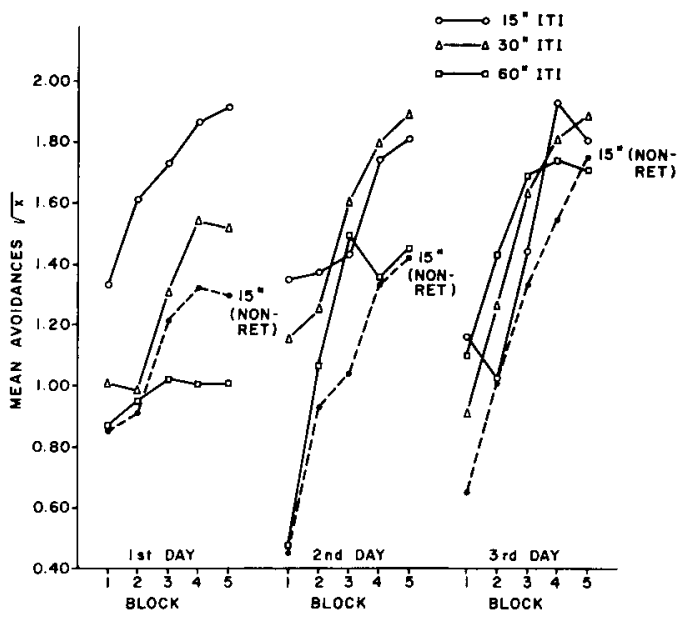

Fig. 1. Avoidance data for each session in blocks of ten trials. The parameter is ITI. Each curve represents the average of the three groups run at a particular ITI. The dashed line represents the average of the three groups in the non-retractable lever condition. 
for each $\mathrm{S}$. These scores for each rat were then averaged to provide the group means. For each day, an analysis of variance was performed for the nine retractablelever groups. An analysis of variance was also performed for each day comparing the non-retractablelever groups with the comparable retractable-lever groups (ITI = 15 sec.).

Figure 1 presents the data for each day, in blocks of 10 trials. Each curve represents the average of three groups run at a particular ITI. The analogous curves with CS-UCS interval as the parameter are not shown since this variable did not produce significant differences.

All groups improved with trials on each day, but in no case did trials interact with one of the experimental variables (smallest $F$ for the "trials" factor was on Day $1, F=5.36$, df $=4 / 288, p<.001$ ).

For Day 1 the ITI variable was highly significant $(F=6.67$, df $=2 / 72, p<.005)$ with the shorter ITIs producing the best avoidance responding. The effect of the CS variable did not achieve significance $(F=1.68$, $\mathrm{df}=2 / 72, \mathrm{p}<.20$ ), nor did the interaction between ITI and CS-UCS interval.

For Day 2, however, none of the experimental variables produced a significant effect. The only variable that approached significance was the ITI $(F=1.94$, $\mathrm{df}=2 / 72, .10<\mathrm{p}<.20$ ) which had been highly significant on the previous day.

On Day 3, none of the experimental variables approached significance.

The results for the retractable and non-retractable 15 sec. ITI groups show trends similar to those found for the retractable groups alone. On Day 1, the retractable-lever groups are better avoiders than their non-retractable-lever counterparts by a highly significant margin ( $F=10.74, \mathrm{df}=1 / 48, \mathrm{p}<.005$ ). The CS-UCS interval is also significant $(F=4.84, \mathrm{df}=2 / 48, .01<\mathrm{p}<$ $.025)$, evidently because the groups with a 3 sec. CS are relatively poor avoiders. The analysis for the second day indicates that these differences continue to be significant. The retractable-non-retractable variable is now significant at the .025 level $(F=6.42$, $\mathrm{df}=1 / 48, .01<\mathrm{p}<.025$ ), while the CS-UCS interval variable is significant at the .05 level $(\mathrm{F}=3.30, \mathrm{df}=$
$2 / 48$, $.025<p<.05)$. By the third day the effects of our experimental variables no longer approached significance.

\section{Discussion and Conclusions}

The results are quite consistent in that several variables are shown to affect avoidance responding on the first day of training, but their effects are negligible or sharply reduced by the second day, and completely eliminated by the third.

The shorter intervals produced better performance in agreement with Pearl's work with lever-press avoidance (1963). Thus, despite the discrete nature of the retractable lever procedure, the present results coincide with the continuous lever-press avoidance data and not with the shuttlebox data, for which Brush has reported a positive relation between avoidance and ITIs up to $5 \mathrm{~min}$. (Brush, 1962). However, the discrete nature of the retractable lever procedure indicates that Pearl's explanation of the superiority of the shorter ITIs in terms of the perseveration of lever-pressing is inadequate. None of our animals could perseverate lever-pressing by the very nature of the situation.

The CS-UCS interval exerted less influence on the course of avoidance learning than the ITI, with differential effects restricted to the shorter (15 sec.) ITI. What differences there are seem to be caused by the poor performance of the 3 sec. CS-UCS group.

\section{References}

Bitterman, M. E. The CS-UCS interval in classical and avoidance conditioning. In W. F. Prokasy (Ed.), Classical conditioning. New York: Appleton-Century-Crofts, 1965.

Brush, F. R. The effects of intertrial interval on avoidance learning in the rat. J. comp. physiol. Psychol, 1962, 55, 888-892.

Fantino, E., Sharp, D., \& Cole, M. Factors facilitating lever-press avoidance. J. comp. physiol. Psychol., 1966, in press.

Low, L. A., \& Low, A. I. Effects of CS-UCS interval length upon avoidance responding. J. comp. physiol. Psychol., 1962, 55, 1,059-61.

Pearl, J. Intertrial interval and acquisition of a lever press avoidance response. J. comp. physiol. Psychol., 1963, 56, 710-712.

\section{Notes}

1. Research supported by NIH Grant MH-11180-01 to Michael Cole and by NSF Grant GB-3626 to Edmund Fantino.

2. Now at University of California at Irvine. 